Check for updates

Cite this: Chem. Commun., 2017, 53,6136

Received 13th April 2017,

Accepted 11th May 2017

DOI: $10.1039 / \mathrm{c} 7 \mathrm{cc} 02767 \mathrm{~b}$

rsc.li/chemcomm

\section{Palladium-catalysed atom-economical synthesis of conjugated dienals from terminal acetylenes and acrolein $\uparrow$}

\author{
Zoë Hearne (D) and Chao-Jun Li (D)*
}

Conjugated $(E, E)$-dienals are versatile synthetic intermediates owing to their trifunctional, electrophilic nature and the prevalence of the $(E, E)$-diene in a wide range of functional molecules. It is shown herein that $(E, E)$-dienals can be readily prepared in two palladium-catalysed steps from simple, unactivated starting materials; terminal acetylenes and acrolein can be coupled via conjugate addition, followed by alkyne isomerisation. This procedure provides a highly atomeconomical, redox-neutral and practical method to prepare a range of conjugated $(E, E)$-dienals in good yields and diastereoselectivities.

Conjugated $(E, E)$-dienals have demonstrated value as highly versatile synthetic intermediates en route to functional molecules. The $(E, E)$-diene component of their structure is one of the most commonly recurring motifs in natural products (Fig. 1A), ${ }^{1}$ and they are valuable substrates as they can be readily derivatized owing to their trifunctional, electrophilic nature: featuring both an aldehyde and two conjugated alkenes. Studies on the manipulation of dienals for exclusive $1,2-{ }^{2}, 1,4-{ }^{3}$ or 1,6 -addition ${ }^{4}$ draw attention to their flexible and tunable reactivity. Furthermore, dienals can be cyclised to access polycyclic indolines, ${ }^{5}$ cyclobutanones, ${ }^{6}$ chromans, $^{4}$ cyclohexanones ${ }^{7}$ and isoxazolidines. ${ }^{8}$ Profiting from this synthetic versatility, conjugated $(E, E)$-dienals have featured in the synthesis of many functional molecules with varied applications, including pharmaceuticals, ${ }^{9}$ polyene pheromone natural products, ${ }^{10}$ and organic chromophores for technological applications (for example OLEDs and molecular wires). ${ }^{11}$

Despite the broad utility of conjugated $(E, E)$-dienals, existing methods for their synthesis are not straightforward. Classical approaches such as Wittig $^{12}$ or Horner-Wadsworth-Emmons ${ }^{13}$ olefination reactions suffer from low atom economy, poor diastereoselectivity, and harsh reaction conditions. Recent

Department of Chemistry, FQRNT Centre for Green Chemistry and Catalysis,

McGill University, 801 Sherbrooke Street West, Montréal, Quebec H3A OB8,

Canada.E-mail: cj.li@mcgill.ca

$\dagger$ Electronic supplementary information (ESI) available: Experimental procedures and characterisation data for all products and substrates, IR and NMR spectra for all products and new compounds, crystallographic details. CCDC 1527924. For ESI and crystallographic data in CIF or other electronic format see DOI: 10.1039/c7cc02767b

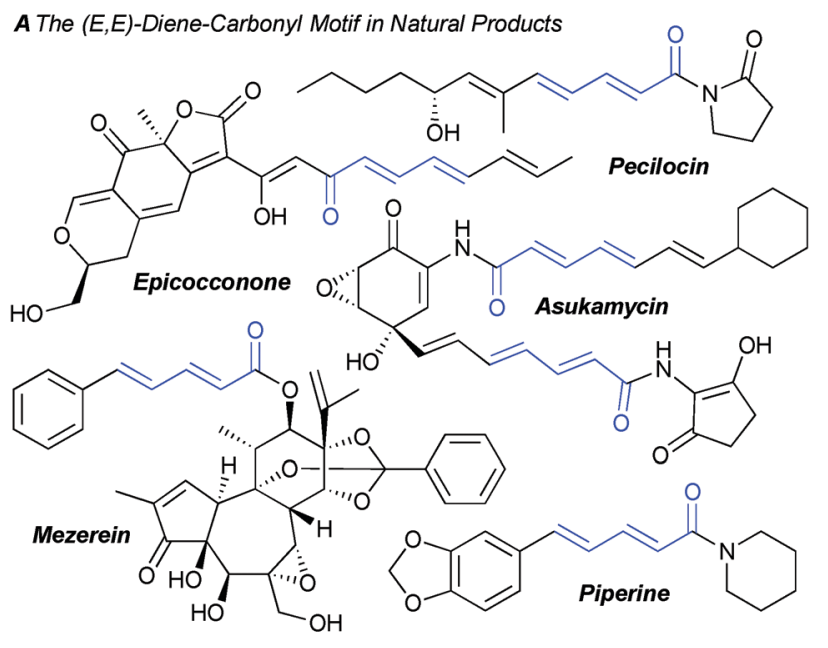

B Palladium-Catalysed Synthesis of 4-Alkynals
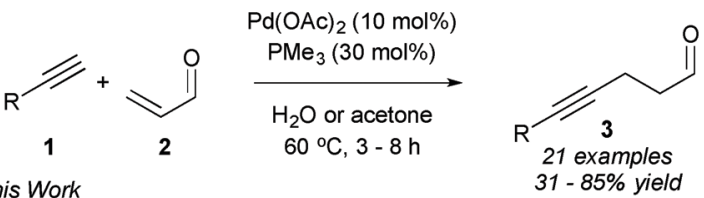

c This Work<smiles>[R]C#CCCC=O</smiles>

$\mathrm{Pd}(\mathrm{OAc})_{2}(10 \mathrm{~mol} \%)$ dpph $(20 \mathrm{~mol} \%)$

$\mathrm{AcOH} / \mathrm{NaOAc}$ (50 mol\%) 1,4-dioxane or toluene $90{ }^{\circ} \mathrm{C}, 2-16 \mathrm{hrs}$

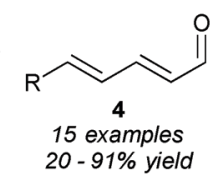

Fig. 1 Ready access to a variety of natural products would be facilitated by a practical method to prepare versatile building blocks, such as conjugated $(E, E)$-dienals.

contributions have offered elegant solutions to the challenge of preparing conjugated $(E, E)$-dienals, for example by propargyl vinyl ether ${ }^{14}$ or methylenecyclopropane rearrangements, ${ }^{15}$ organocatalytic oxidation, ${ }^{16}$ and other strategies. ${ }^{17}$ However, in such cases synthesis of the required starting materials requires multiple steps and stoichiometric reagents, and many lack generality. To fully realise the potential of conjugated $(E, E)$-dienals in synthesis, the 
development of a practical, expedient and mild procedure for their formation would have great value. We were inspired by the literature concerning palladium-catalysed isomerisation reactions of alkynes to yield $(E, E)$-dienes, ${ }^{18,19}$ a field launched by the groups of Trost, ${ }^{20,21} \mathrm{Lu},{ }^{22}$ and Imaizumi, ${ }^{23}$ who first studied

Table 1 Optimisation of the reaction conditions ${ }^{a}$

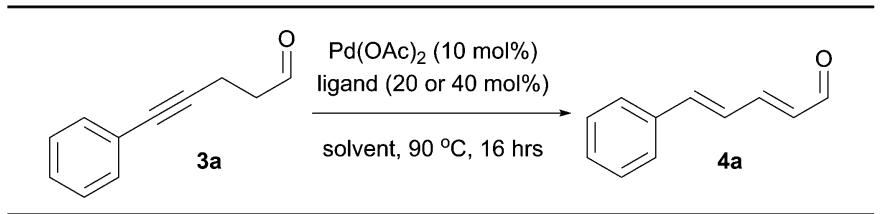

\begin{tabular}{lllll}
\hline Entry & Ligand & Pd/L pre-mix temp. ${ }^{b}\left({ }^{\circ} \mathrm{C}\right)$ & Additive $^{c}$ & \% $^{\text {Yield }}{ }^{d}$ \\
\hline 1 & $\mathrm{PPh}_{3}$ & 25 & None & 57 \\
2 & dppp & 25 & None & 23 \\
3 & dppb & 25 & None & 40 \\
4 & dppe & 25 & None & 68 \\
5 & dppf & 25 & None & 69 \\
6 & dpph & 25 & None & 81 \\
7 & dpph & 60 & None & 80 \\
8 & dpph & 100 & None & 59 \\
9 & dpph & None & None & 75 \\
10 & dpph & None & AcOH/NaOAc & 90 \\
$11^{e}$ & dpph & None & AcOH/NaOAc & 95 \\
$12^{e}$ & none & None & AcOH/NaOAc & 0 \\
$13^{e f f}$ & dpph & None & AcOH/NaOAc & 0
\end{tabular}

${ }^{a}$ Reaction carried out with $3 \mathrm{a}(0.2 \mathrm{mmol}, 1.0$ equiv. $), \mathrm{Pd}(\mathrm{OAc})_{2}$ ( $0.02 \mathrm{mmol}, 10 \mathrm{~mol} \%$ ), phosphine ligand ( 20 or $40 \mathrm{~mol} \%$ for bidentate and monodentate phosphines, respectively), solvent (1 mL, $0.2 \mathrm{M})$, $90{ }^{\circ} \mathrm{C}$ for 16 hours. ${ }^{b}$ Catalyst pre-formation: a mixture of the catalyst and ligand in THF $(0.5 \mathrm{~mL})$ was stirred under argon for one hour. ${ }^{c} 50 \mathrm{~mol} \%$. ${ }^{d}$ Yields calculated by ${ }^{1} \mathrm{H}$ NMR analysis of crude reaction mixtures using 1,3,5-trimethoxybenzene internal standard. ${ }^{e} 1,4$-Dioxane solvent. ${ }^{f}$ No $\mathrm{Pd}(\mathrm{OAc})_{2}$ added. the transition-metal and organo-catalysed isomerisation of 4 -alkynones to $(E, E)$-dienones. It was envisioned that just two palladium-catalysed steps could be used to access $(E, E)$-dienals; conjugate addition of terminal acetylenes (1) and acrolein (2) would return 4-alkynals (3, Fig. 1B), followed by isomerisation of the alkyne (Fig. 1C). This would provide a rapid and atomeconomical access to conjugated $(E, E)$-dienals (4).

Having recently succeeded in developing a palladium-catalysed conjugate addition to prepare 4 -alkynals, ${ }^{24}$ herein is described the atom-economical and redox-neutral method for the diastereoselective isomerisation of a broad range of 4-akynals (3) to conjugated $(E, E)$-dienals $(\mathbf{4})$ in moderate to good yields. Relatively mild and operationally simple reaction conditions, combined with ready access to the alkyne substrates, make this approach advantageous for the synthesis of such versatile synthetic intermediates.

Studies began (Table 1) with testing conditions first reported by Trost and co-workers for the palladium-catalysed isomerisation of 2-alkynones to conjugated $(E, E)$-dienones. ${ }^{20} \mathrm{~A}$ palladium catalyst was used, pre-formed from $\mathrm{Pd}(\mathrm{OAc})_{2}(10 \mathrm{~mol} \%)$ and triphenylphosphine $(40 \mathrm{~mol} \%)$ in THF solvent $(0.2 \mathrm{M})$ under argon at room temperature for one hour. A 57\% yield of the alkyne-isomerised product 4a (entry 1) was obtained from substrate $\mathbf{3 a}$ after stirring with the pre-formed catalyst for 16 hours at $90{ }^{\circ} \mathrm{C}$. A survey of ligands revealed that bidentate phosphines were beneficial to this transformation (entries 2-6), particularly those with large bite-angles such as 1,1'-ferrocenediyl-bis(diphenylphosphine) (dppf, entry 5) and 1,6-bis(diphenylphosphino)hexane (dpph, entry 6). Catalyst pre-formation at 25 or $60{ }^{\circ} \mathrm{C}$ conferred little benefit (entries 6, 7 and 9), while stirring the catalyst components at $100{ }^{\circ} \mathrm{C}$ reduced the product yield to $59 \%$ (entry 8 ). Adding a sodium acetate/acetic acid buffer improves the yields
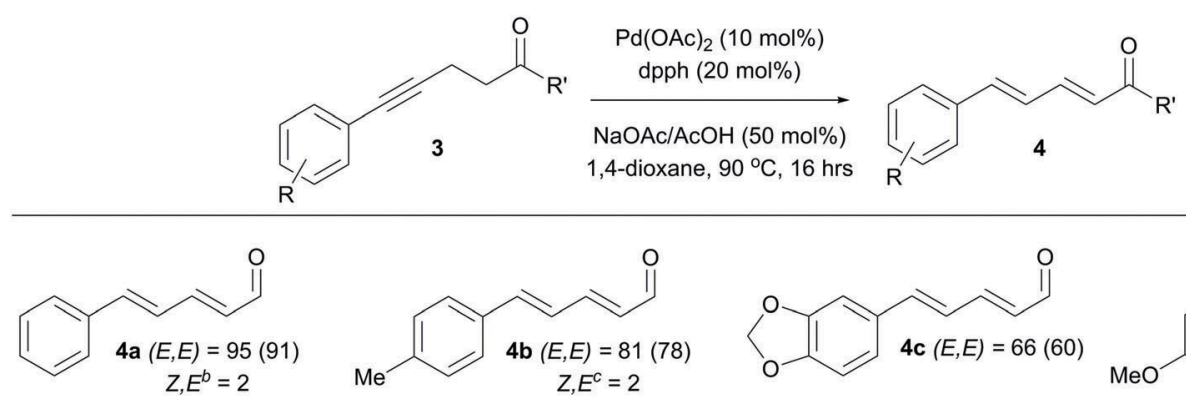<smiles>O=C/C=C/C=C/c1ccc2c(c1)OCO2</smiles>

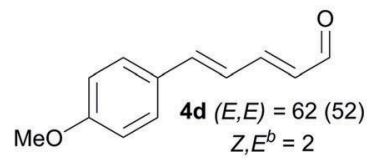

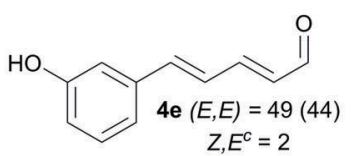

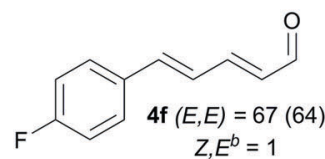<smiles>COC(=O)c1ccc(C=CC=CC=CC=O)cc1</smiles><smiles>O=C/C=C\C=C\c1cccnc1</smiles><smiles>O=C/C=C/C=C/c1cccs1</smiles><smiles>CCC(=O)/C=C/C=C/c1ccccc1</smiles><smiles>COC(=O)/C=C/C=C/c1ccccc1</smiles><smiles>CC1=CC(C)=C(C)C(C)C1C(C)C(C)C(C)C(C)C(C)=C(C)C</smiles>

Fig. 2 Isomerisation of aromatic-substituted 4-alkynals catalysed by $\mathrm{Pd}(\mathrm{OAc})_{2} / \mathrm{dpph}$ in 1,4-dioxane. ${ }^{a}$ All reactions were carried out with $3(0.2 \mathrm{mmol}$, 1.0 equiv.), $\mathrm{Pd}(\mathrm{OAc})_{2}(0.02 \mathrm{mmol}, 10 \mathrm{~mol} \%)$, dpph (0.04 mmol, $\left.20 \mathrm{~mol} \%\right), \mathrm{NaOAc}(0.1 \mathrm{mmol}, 50 \mathrm{~mol} \%), \mathrm{AcOH}(0.1 \mathrm{mmol}, 50 \mathrm{~mol} \%), 1,4-\mathrm{dioxane}(1 \mathrm{~mL})$, $90{ }^{\circ} \mathrm{C}, 16$ hours reaction time. NMR yields are shown, isolated yields are in parentheses. ${ }^{b} \mathrm{NMR}$ yield of minor isomer determined by ${ }^{1} \mathrm{H}$ NMR spectral analysis of crude reaction mixtures, and characterized by $1 \mathrm{D}$ selective- ${ }^{1} \mathrm{H}$ TOCSY NMR. ${ }^{C}$ NMR yield and characterisation of minor isomers by analogy to 4 a. 
slightly to $90 \%$ (entry 10 ). The solvent was changed from THF to 1,4-dioxane, the boiling point of which is higher than the reaction temperature, thus ensuring temperature consistency (entry 11). Control reactions, without palladium catalyst or phosphine ligand (entries 12 and 13, respectively) gave no product.

The scope of the reaction was tested using a range of aryl and aliphatic substrates (Fig. 2). The phenyl-substituted substrate 3a gave an excellent 95\% yield, and aryl substrates bearing electron-rich (3b-3d) and electron-poor (3f, 3g) substituents isomerised in good yields (62-81\%). Aryl substrates with free-

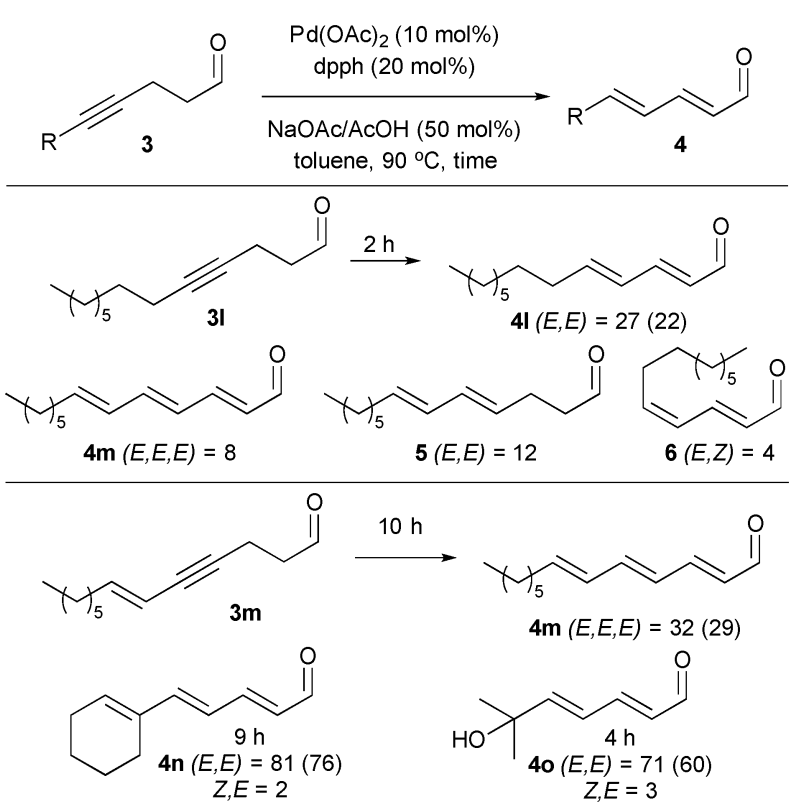

Fig. 3 Isomerisation of aliphatic-substituted 4-alkynals catalysed by $\mathrm{Pd}(\mathrm{OAc})_{2} / \mathrm{dpph}$ in 1,4-dioxane. All reactions were carried out with 3 (0.2 mmol, 1.0 equiv.), $\mathrm{Pd}(\mathrm{OAc})_{2}(0.02 \mathrm{mmol}, 10 \mathrm{~mol} \%)$, dpph $(0.04 \mathrm{mmol}$, $20 \mathrm{~mol} \%), \mathrm{NaOAc}(0.1 \mathrm{mmol}, 50 \mathrm{~mol} \%), \mathrm{AcOH}(0.1 \mathrm{mmol}, 50 \mathrm{~mol} \%)$, toluene $(1 \mathrm{~mL}), 90{ }^{\circ} \mathrm{C}$. Reaction time (in hours) is shown, followed by NMR yields, and isolated yields in parentheses. Minor products characterised by 2D NMR and/or 1D selective- ${ }^{1} \mathrm{H}$ TOCSY NMR. hydroxyl (3e), basic (3h) and heterocyclic (3h \& 3i) substituents isomerised in moderate yields (44-49\%). The optimised reaction conditions were also successfully applied to 4-alkynones and 4 -alkynoates, achieving very good yields of dienones $(4 \mathbf{j}, 88 \%)$ and dienoates $(\mathbf{4 k}, 80 \%)$, respectively. To demonstrate synthetic viability the reaction was scaled-up by applying slightly modified conditions to $800 \mathrm{mg}$ ( $5.1 \mathrm{mmol})$ of 3a. After stirring for 15 hours at $95{ }^{\circ} \mathrm{C}$, a gratifying yield of $69 \%$ of 4 a was obtained. Diastereoselectivity of the process for the $(E, E)$-isomer was consistently high, with diastereomeric ratios (dr) ranging from $25(E, E): 1(Z, E)$ to $67(E, E): 1(Z, E)$. An exception was thiophenyl-substituted compound 4i, which had reduced diastereoselectivity $(\mathrm{dr}=$ $11(E, E): 1(Z, E): 2(E, Z))$. The $(E, E)$-stereochemistry of the major products was confirmed by single-crystal X-ray diffraction of representative compound $\mathbf{4 h}$ (Fig. 2).

The reaction conditions for aliphatic substrates were optimised using octyl-substituted substrate $\mathbf{3 l}$ (Fig. 3). Reducing the reaction time and switching to toluene as the solvent increased the yield from $13 \%$ to $27 \%$, but despite further optimisation the quantity of 41 remained low. Efforts were hampered by poor regioselectivity; 4,6-dienal 5 forms in appreciable quantities. Regioselectivity was poor because unactivated, aliphatic alkynes such as $\mathbf{3 1}$ have little electronic bias; the alkyne can isomerise in either direction, giving dienals $\mathbf{4 l}$ and 5. Side-product formation of the (E,Z)-stereoisomer 6 and trienal $4 \mathbf{k}$ also reduced the yield of the desired product $4 \mathbf{l}$. Synthesis of a number of aliphatic dienals (4o) and trienals (4m and $4 n$ ) was successfully realised using substrates which have $\mathrm{sp}^{3}$ $\alpha$ and $\beta$ protons on only one side of the alkyne (Fig. 3). Efforts to improve selectivity to favour the 2,4-dienal are underway in our laboratory.

Two alternative mechanisms are proposed. The first (A, Fig. 4) invokes a palladium-hydride as the active catalyst and proceeds by hydropalladation/dehydropalladation, while the second (B, Fig. 4) involves an acetate-assisted $\mathrm{C}-\mathrm{H}$ activation. Participation of a metal-hydride has been favoured in the literature for related transformations. ${ }^{18,20}$ In this mechanism (Fig. 4A) palladium(0) forms by reduction of palladium(II)

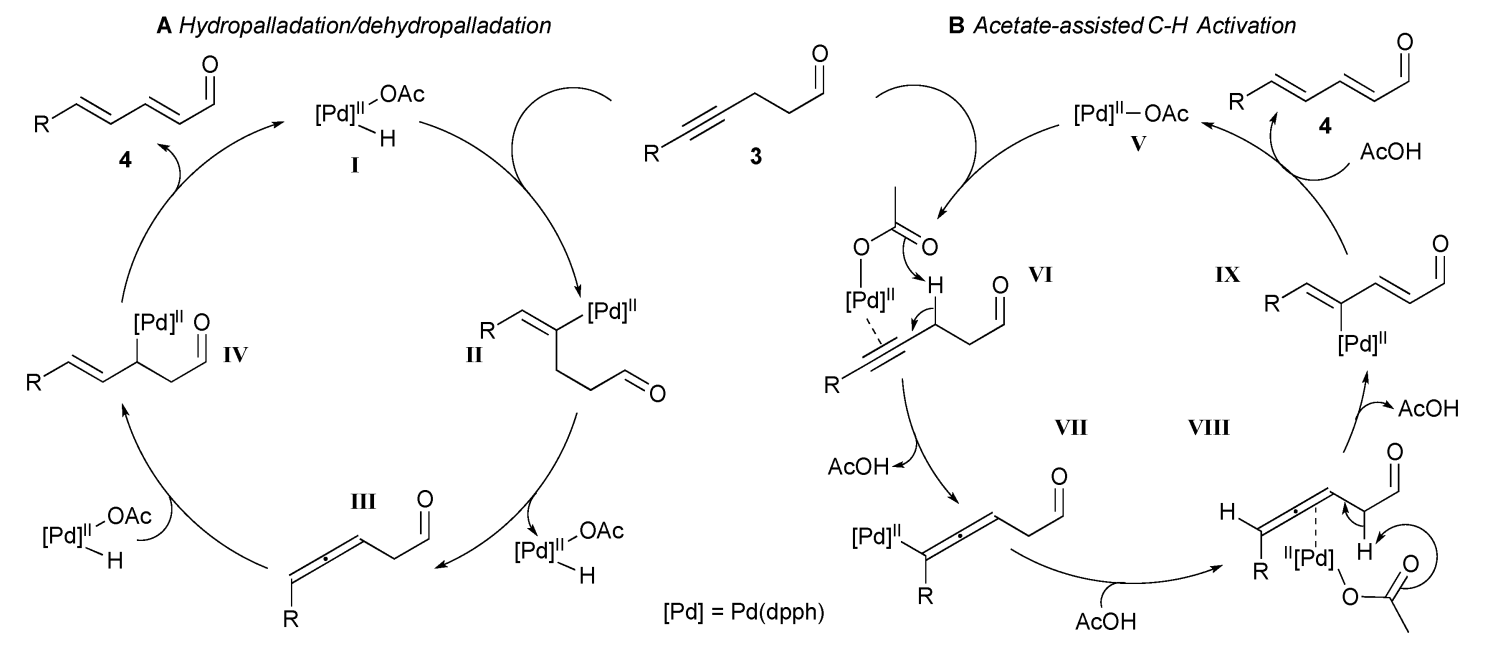

Fig. 4 Proposed mechanisms for the isomerisation of 4-alkynals to conjugated $(E, E)$-dienals. 
acetate with excess phosphine. The spontaneous nature of this process has been demonstrated for similar systems. ${ }^{25}$ Oxidative addition of acetic acid generates a palladium(II) hydride (I), which adds to the alkyne (7) in a syn fashion to generate a vinyl palladium species (II). Dehydropalladation returns an allene intermediate (III). A second hydropalladation gives allylpalladium (IV) and $\beta$-hydride elimination returns the product (4) and re-generates the active palladium-hydride (I). Detection of either the metal-hydride or the allene was attempted by running the reaction in a sealed tube under argon using high-temperature NMR, but no resonances corresponding to either intermediate were observed. This does not exclude the involvement of a metalhydride; the active-catalyst and allene may be too short-lived to be seen, or in the case of the allene may remain bound to palladium.

A second mechanism operating under the reaction conditions can also be envisioned (Fig. 4B), proceeding by acetate-assisted deprotonation in a similar fashion to the proposed mechanism for carboxylate-assisted $\mathrm{C}-\mathrm{H}$ activation of arenes and enolates. Palladium(II) species bound to bidentate phosphine ligands are alkynophilic, and upon coordination can increase the electrophilicity of the alkyne, ${ }^{26}$ increasing the acidity of the $\alpha$-protons. Subsequent intra-molecular deprotonation by a bound acetate ligand (VI) might give a $\sigma$-allenyl palladium complex. Protiodepalladation of this intermediate gives an allene (VIII). A second iteration; acetate-assisted deprotonation of the $\alpha$-protons to give vinylpalladium IX, followed by protiodepalladation, returns the product (4).

In conclusion, a practical and original method to access conjugated $(E, E)$-dienals via palladium-catalysed isomerisation of 4-alkynals has been realised. The highly atom-economical and redox-neutral process provides rapid access to conjugated $(E, E)$-dienals in moderate to good yields and broad scope. The products can be transformed into a variety of functional groups, and have been proven to be useful and versatile intermediates en route to a broad range of functional molecules. The synthetic method is a valuable addition to existing methods used to synthesise dienals, and employs readily accessible substrates, economical choices of catalyst and ligand, and a simple operation. Further efforts will be dedicated to understanding the reaction mechanism, and improving the substrate scope and yields.
We are grateful to the Canada Research Chair (Tier 1) Foundation (to C.-J. Li), the Fonds de Recherche du Québec Nature et Technologies, Natural Sciences and Engineering Research Council of Canada, CFI, and L'Oréal R\&I for their support of our research. We are grateful to Igor Huskic for solving the crystal structure of product $\mathbf{4 h}$.

\section{References}

1 E. M. Woerly, J. Roy and M. D. Burke, Nat. Chem., 2014, 6, 484.

2 P. Zhang and J. P. Morken, J. Am. Chem. Soc., 2009, 131, 12550.

3 Y. Hayashi, D. Okamura, S. Umemiya and T. Uchimaru, ChemCatChem, 2012, 4, 959.

4 P. H. Poulsen, K. S. Feu, B. M. Paz, F. Jensen and K. A. Jørgensen, Angew. Chem., Int. Ed., 2015, 54, 8203.

5 A.-S. Marques, V. Coeffard, I. Chataigner, G. Vincent and X. Moreau, Org. Lett., 2016, 18, 5296.

6 Ł. Albrecht, G. Dickmeiss, F. C. Acosta, C. Rodríguez-Escrich, R. L. Davis and K. A. Jørgensen, J. Am. Chem. Soc., 2012, 134, 2543.

7 K. Tanaka, Y. Hagiwara and M. Hirano, Eur. J. Org. Chem., 2006, 3582.

8 Q. Y. Dou, Y. Q. Tu, Y. Zhang, J. M. Tian, F. M. Zhang and S. H. Wang, Adv. Synth. Catal., 2016, 358, 874.

9 M. Sugi, R. Nagase, T. Misaki, H. Nakatsuji and Y. Tanabe, Eur. J. Org. Chem., 2016, 4834; Y. Hu and H. G. Floss, J. Am. Chem. Soc., 2004, 126, 3837.

10 P.-F. Li, H.-L. Wang and J. Qu, J. Org. Chem., 2014, 79, 3955.

11 P. An, N.-S. Xu, H.-L. Zhang, X.-P. Cao, Z.-F. Shi and W. Wen, Chem. Asian J., 2015, 10, 1959; J. S. Meisner, D. F. Sedbrook, M. Krikorian, J. Chen, A. Sattler, M. E. Carnes, C. B. Murray, M. Steigerwald and C. Nuckolls, Chem. Sci., 2012, 3, 1007.

12 C. W. Spangler and R. K. McCoy, Synth. Commun., 1988, 18, 51.

13 P. H. Poulsen, S. Vergura, A. Monleón, D. K. B. Jørgensen and K. A. Jørgensen, J. Am. Chem. Soc., 2016, 138, 6412.

14 S. E. Motika, Q. Wang, X. Ye and X. Shi, Org. Lett., 2015, 17, 290.

15 M. Shi, G.-Q. Tian and J. Li, Tetrahedron, 2009, 65, 3404.

16 X. Chen, Y. Zhang, H. Wan, W. Wang and S. Zhang, Chem. Commun., 2016, 52, 3532.

17 N. Vicart, D. Castet-Caillabet, Y. Ramondenc, G. Plé and L. Duhamel, Synlett, 1998, 411; A. Capperucci, A. Degl'Innocenti, P. Dondoli, T. Nocentini, G. Reginato and A. Ricci, Tetrahedron, 2001, 57, 6267. 18 Z. Wang and X. Lu, Tetrahedron, 1995, 51, 11765.

19 H. Yasui, H. Yorimitsu and K. Oshima, Synlett, 2006, 1783.

20 B. M. Trost and T. Schmidt, J. Am. Chem. Soc., 1988, 110, 2301.

21 B. M. Trost and U. Kazmaier, J. Am. Chem. Soc., 1992, 114, 7933.

22 D. Ma, Y. Lin, X. Lu and Y. Yu, Tetrahedron Lett., 1988, 29, 1045; C. Guo and X. Lu, J. Chem. Soc., Perkin Trans. 1, 1993, 1921.

23 Y. Inoue and S. Imaizumi, J. Mol. Catal., 1988, 49, L19.

24 H. Wang, Z. Hearne, T. Knauber, M. Dalko, J. Hitce, X. Marat, M. Moreau and C.-J. Li, Tetrahedron, 2015, 71, 5866.

25 C. Amatore, A. Jutand and A. Thuilliez, Organometallics, 2001, 20, 3241. 26 J. A. Tunge and L. N. Foresee, Organometallics, 2005, 24, 6440. 